\title{
高中语文整本书阅读的小说教学对策分析
}

陈丽玲

甘肃省民乐县第一中学

DOI:10.32629/jief.v2i4.1229

[摘 要] 随着我国新课改的实行下, 语文教学跟随改革的潮流不断向前发展, 在目前的语文教育领域中整本书阅读潮流备受社会各界的关注。 但是，受实际的教学水平和环境的局限，整本书的阅读思想还不能在具体的教学活动中落实。现在社会上的学术研究关注点在整本书阅读思 想上只是停留在理论讨论阶段。整本书的阅读思想只停留在理论阶段是不够的，最重要的还是要落实在教学中去。所以，本文以小说为高中 语文阅读教学中的对象对整本书的阅读思想进行分析讨论。

[关键词] 高中语文; 整本书阅读; 小说教学

中图分类号: G633.3 文献标识码：A

当今, 社会上网络时代发达, 在这种网络时代下快餐文化冲击着人 们的生产生活。尤其是在读书阅读上, 简单化、碎片化的阅读形式在学 生阅读方面越来越流行, 但是学生的阅读能力在这种趋势下逐渐下降。 浅表形势的阅读方式给学生们带来了许多大量且无用的信息, 浪费了学 生们珍贵的学习时间, 高中生的阅读中展开整本书阅读方式是非常有必 要的。许多学者和一线教育工作者为了使整本书的阅读顺利地开展, 对 语文教学工作进行不解的探索和尝试。许多教学工作语文者发现小说的 教学与课内外教学模式不一致, 语文整本书阅读中小说教学课堂学习时 间不够, 不合理的内容和教学方式的不正确等诸多问题, 对此, 本文展 开了整本书阅读的小说教学进行有关分析与讨论。

\section{1 整本书阅读在高中语文小说中的应用现况}

1.1 缺少教学规划, 学习任务不清晰

小说的整本书阅读在教学过程中虽然非常重要, 但是许多的学校和 教学机构却没有给它制定出单独的学习课程, 只是为了达到新课改的要 求。一些语文教师在进行这项教学活动时缺乏对学生的专业性指导, 只 是单一的让学生去认真阅读但如何读, 抱着什么样的目标去读并没有给 出指导, 更不用说对整本书阅读制定相应的读书计划了。另外, 学生们 对其提不起兴趣，按照自己的懒惰形式对阅读实行 “放羊式” 的阅读， 没有对其形成良好的目标和目的。

1.2 教学观念单一, 课程类型缺少多样性

从新课改施行以来, 有些学校已转变了以往的腐朽的教学理念, 开 始实行属于自己学生发展的教学策略, 但是现在仍然有一些学校还进行 传统的教育思想, 他们认为语文学科的综合素养依旧是通过题海战术来 提高, 而对于高考来说, 整本书阅读并没有太大成效, 所以高中时期的 整本书阅读就没有得到更好的发展。小说阅读看似比较新颖有趣但是课 程一旦开设学生在其中更是得不到自身能力的发展。教师教学中关于小 说的教学理念腐旧, 在阅读课程上类型也比较单一, 甚至在小说教学上, 教师碰到小说阅读就对其展开三要素的教学方式。教学模式的单一让学 生体会不到小说中的情感感受, 又无法使学生的阅读能力得到提高, 另 外教师在这种教学模式下也会感到乏味。

1.3 整本书阅读教学模式在小说的教学模式中呈现固化的现象

整本书阅读在当今的语文整体教学中处于重要的地位, 但是语文教 师在教学中却没有得到重视, 仍然沿用以往传统的固化教学模式。整本 书阅读在语文中起到的效果并不会立即见效, 并且和教学成效的评价没 有关系, 导致了教师难以主动去只因学生进行阅读。另一个层面, 学校 对学生的考察形式呈现程序化的特征, 题目在语文试题考查中总是同一 类型, 久而久之学生就失去了对整本书阅读的阅读兴趣。

\section{2 在高中语文小说教学中运用整本书的教学理念的对策}

2.1 立足于教材, 规划合理的教学目标
在语文教学中, 教学目标的明确不仅能让教师加深对文本内容的理 解, 而且对于学生的学习也存在着一定的引领作用。因此, 在确定好整 本书的教学目标前, 教师要明确指导学生阅读某一本书的目的, 这本阅 读书籍和教材存在哪种联系。在指导学生对于《林黛玉入贾府》这一课 时, 教师可以引进《红楼梦》这一整本书的阅读, 并结合学生的实际情 况制定教学活动。教学目标的制定要更重视学生的语言表达能力和语文 阅读能力以及书面的表的能力等。

2.2 立足于学生实际情况, 制定教学方法

学生提升学习能力的关键在于教师指定的教学方法, 合理的教学内 容有利于教学质量的提高。在整本书的教学中, 教师要依据学生的学习 情况和教学的进行情况对教学内容进行优化整理, 使之能更好的服务于 教学目标。另外, 教师还要为学生搭建适于学生自身发展的学习平台, 更好的利用现有信息资源, 来帮助学生们拓宽阅读的广度和深度。传统 的教学模式往往是教师处于主体位置, 学生则处于被动的接受位置, 教 师要改变这种陈旧的教学, 把教师自身解放出来, 让学生做阅读的主体, 发挥学生的自主学习能力。

2.3 立足于整体, 提高学生的思维能力

在以往的教学模式中, 教师的教学都是按照教材的进度进行教学活 动的, 对于小说教学也是一篇一篇的分析, 通过反复的锻炼下, 学生也 只是掌握了单片的阅读技巧。冊庸置疑的是, 单篇阅读能力是语文综合 素养的重要组成部分。但是学生只掌握单篇阅读技巧是远远不够的, 在 面对整本书阅读时, 反而会误解他们的阅读路径, 也没法从整体上赏析 阅读。所以，在阅读教学中教师要注重文章的整体性教学。整体性阅读 中, 教师带领学生阅读整个小说集只是一个过程, 而不是阅读的真正目 的, 要在阅读中把以往的经验和阅读中的经验相结合, 才能使阅读的知 识转化为自身的语文素养。所以, 教师要注意牵引训练在学生身上发挥 的重要作用，让其立足于整体，在整体中寻找发展。

\section{3 结束语}

总而言之, 整本书的阅读教学要通过工作者的不解努力去推广进行, 合理的对学生进行引导, 整合教学内容, 改善教学方法进而提高高中小 说中整体阅读的阅读成效。

\section{[参考文献]}

[1]刘黎.高中语文小说类文本整本书阅读教学路径分析 [J].考试周 刊, 2019(20):66-66.

[2]陈延春.高中语文整本书阅读教学的优势及方法指导探略[J].课 外语文,2019(7):131-132.

[3]金勇。“微课”应用于高中语文教学的价值探寻 [N]. 科学导 报,2020-08-28(B03). 